\title{
ÇAVUŞCUGÖL LİNYİT AÇIK OCAĞINDAKİ DURAYSIZLIKLARIN İNCELENMESİ
}

\author{
${ }^{1}$ Hakan ÖZŞEN ${ }^{(1)}$, 2Berk KAYGUSUZ, ${ }^{3}$ Dursun KAYA \\ Konya Teknik Üniversitesi, Mühendislik ve Doğa Bilimleri Fakültesi, Maden Mühendisliği Bölümü, \\ Konya, TÜRKIYE \\ 1hozsen@ktun.edu.tr, 2b.kaygusuz@cinergroup.com.tr , ${ }^{3}$ dursun.kaya@hotmail.com
}

(Geliş/Received: 09.05.2019; Kabul/Accepted in Revised Form: 11.06.2019)

ÖZ: Maden açık ocaklarında, mühendislik çalışmaları ile oluşturulan şevlerde, karayolu ve demiryolu yarmalarında ve doğal şevlerde duraysızlık oluşması durumunda şev kaymaları oluşabilmektedir. Meydana gelen bu kaymalar yaşam kaybına, ekonomik kayıplara, geometrisi bozulan alanlara sebebiyet vermektedir. Bu sonuçların önüne geçebilmek için oluşan duraysızlıkların izlenmesi ve elde edilen sonuçlar neticesinde emniyeti arttırıcı jeoteknik revizyonlar, kaya düşmesini önleyici sistemler gibi önlemlerin alınması gerekmektedir. Bu çalışma, halen Türkiye Kömür İşletmeleri(TKİ) Garp Linyitleri İşletmesi'ne (GLİ) bağlı olan Ilgın-Çavuşcugöl linyit açı ocağında gerçekleştirilmiştir. Ocakta yapılan incelemeler ve denetlemeler neticesinde ocağın doğu şevinin $60 \mathrm{~m}$ ilerisinde bulunan Çavuşcugöl tren istasyonuna yönelimli çekme çatlakları tespit edilmiştir. Bu bölgede 112 günlük süreçte belirli aralıklarla şev hareketleri izlenmiştir. İzlemede ölçüm sistemi olarak jeodezik ölçüm yöntemi kullanılmıştır. Elde edilen veriler sonucunda şevdeki deformasyon hareketleri değerlendirilmiştir. Ardından, bu hareketliliğe bağlı matematiksel bir eşitlik geliştirilmiştir. Geliştirilen model sonuçları ile arazi verileri arasında yüksek regresyon olduğu tespit edilmiştir.

Anahtar kelimeler: Deformasyon, açık ocak, şev duraylhlı̆̆ı, jeodezik ölçüm, matematiksel modelleme

\section{Investigation of Instability Problems in the Çavuşcugöl Open Lignite Mine}

\begin{abstract}
Slope failure may occur in slopes of open pits slopes, engineering works, highway and railway cuts and natural slopes in case of instability. These failures result in loss of life, economic losses and deterioration of the geometry. In order to prevent these undesired results, monitoring the instability on the slopes is essential. safety enhancement geotechnical revisions, rock fall prevention systems etc. must be established according to the results of monitoring studies. This study was carried out in Turkish Coal Enterprises (TKİ) Ilgın-Çavuşcugöl lignite open pit mine. As a result of the investigations and inspections conducted in the quarry, tension cracks were found. directed to Çavuşcugöl train station, which is $60 \mathrm{~m}$ far from the eastern slope of the quarry. Slope movements were monitored at certain intervals in a period of 112 days by using geodetic measurement method as a monitoring system. Deformation data of the slope were evaluated and a mathematical equation based on these movements was then developed. High correlation was determined between model results and real deformation data.
\end{abstract}

Key Words: Deformation, open pit, slope stability, geodetic measurement, mathematical modelling

\section{GİRIŞ̧(INTRODUCTION)}

Şevlerin duraylılı̆̆ının korunması açı ocak madenciliğinde madencilik faaliyetlerinin sağlıklı yapılabilmesi açısından büyük önem taşır. Ocak içerisinde açlan kalıcı ve üretim basamaklarındaki 
şevlerin kaymasının önlenmesi için duraylılığın sağlanması gerekmektedir. Meydana gelebilecek bir şev kayması yaşamsal ve ekonomik kayıplara yol açabilmektedir. Buna bağlı olarak, açı ocak madencilik faaliyetlerinin yürütülmesi için en uygun şev açısının belirlenmesi güvenli bir madencilik çalışmasının yapılabilmesi için en başta gelen unsurdur. Ancak uygulanan kazı yöntemleri, şev geometrisi, depremler, yeraltı su durumu, jeolojik özellikler ve malzeme özellikleri gibi faktörler şev duraylılığını etkilemektedir (Özgenoğlu, 2005). Bu faktörler göz önünde tutularak şevlerin devamlı gözlem altında tutulması, duraylılığın bozulmasına işaret edecek belirtilerin önceden fark edilmesi açısından büyük önem arz eder. Şevlerde izleme ve kontrol etme işlemleri için farklı metotlar bulunmaktadır. Bunlardan bazıları jeodezik ölçümler, çekme çatlağı ve eklemlerde açılma miktarının ölçülmesi, elektronik mesafe ölçerlerin kullanılması, fotogrametrik yöntem, sondaj borusu içerisinden yüzey altında gerçekleşen hareketleri izlemeye yarayan inklinometrik yöntem ve yüzeydeki deformasyonların izlendiği ekstansometrelerdir (Kulaksız, 2012).

Bu metotlardan jeodezik yöntem ile izlemede, duraysız bölgede deformasyon oluşumu beklenen ve beklenmeyen karakteristik yerlerinde noktalar seçilerek bir kontrol ağ 1 oluşturulur. Oluşturulan bu kontrol ağında belirlenen zaman aralıklarında periyodik ölçümler gerçekleştirilir. Neticede bu noktaların koordinatlarındaki değişim istatistik ve matematik test yöntemleri ile hesaplanarak kaydedilir. Son yıllarda da bu konuyla ilgili birçok araştırmacı araziden elde edilen verinin modellenmesi için birçok yeni çalışmalar yapmışlardır. Örneğin Venter ve diğg. (2013), Rio Tindo'da ki Pilbora demir madeninde, jeodezik izleme yöntemlerini kullanarak elde ettiği verileri ters-hız ve hızzaman eğim yöntemlerinde kullanarak heyelanın gerçekleşeceği zaman tahmin etmiş ve tahminleri sonucu hiçbir personel ve makina zarara uğramadan kayma gerçekleşmiştir. Dereli (2010), ÇetinkayaDivriği (Sivas) demiryolunda bulunan şevlerin kinematik kontrollü duraysızlık analizlerini yapmıştır. Akbulut ve diğ. (2013), Afşin-Elbistan Linyitleri İşletmesi Kışlaköy açık ocağında batı ve doğu şevlerindeki duraysızlıkları incelemiş ve oluşabilecek kayma modelini ortaya koymayı amaçlamışlardır. Karagöz ve diğ. (2016) Alipaşa açık ocak albit madeninde meydana gelen heyelanı GPS ile izlemiş ve oluşum nedenlerini araştırmıştır. Carlà ve diğ. (2017) üç farklı heyelanın (Mt. Beni, Vajont ve Stramboli) ve İtalya'daki tarihi şehir duvarının çökme davranışını incelemişlerdir. Ellerindeki veriler ile ters hız yöntemi uygulamışlardır. Vanneschi ve diğ. (2018), Çek Cumhuriyeti Kuzey Bohemya'da bulunan bir açık ocak linyit işletmesindeki şevlerde oluşan çatlakları jeodezik yöntemle izleyerek elde ettikleri verileri kullanarak limit denge duraylılık analizi ile sonlu elemanlar olasilık analizini karşılaştırmışlardır.

Bu çalışmada, TKİ-GLİ'ne bağlı Ilgın-Çavuşcugöl linyit sahası doğu şevlerindeki çekme çatlakları ile belirti veren olası duraysızlık alanlarındaki deformasyonlar jeodezik ölçüm yöntemi ile belirli zaman aralıklarında izlenmiştir. Çalışmada, heyelan oluşabilecek bölgedeki test noktalarının üç boyutlu koordinatlarının değişip değişmediğinin belirlenmesi ve kaymanın önceden tespiti için kontrol ağları kurulmuş ve belirli aralıklarla ölçümler gerçekleştirilmiştir. Bu kapsamda, değişme miktarları kaydedilmiş ve elde edilen zamana bağlı deformasyon hareketlerinden matematiksel bir eşitlik geliştirilmiştir. Ardından da bu eşitlikten elde edilen veriler gerçek verilerle karşılaştırılarak arasında oluşan bağıntılar ve bu bağıntıların istatistiksel doğrulukları belirlenmiştir.

\section{ÇALIŞMA SAHASI(FIELD STUDY)}

Konya İli'ne bağlı Ilgın İlçesi; Konya-Afyon karayolu üzerinde, Konya'nın kuzeybatısında ve Konya'ya $87 \mathrm{~km}$. mesafededir. Çavuşcugöl linyit açık ocağı, Ilgın İlçesi'nin kuzey batısında yer almaktadır. Ocak Ilgın İlçe merkezine $15 \mathrm{~km}$. mesafededir. Ocak yolu asfalt olup yaz kış ulaşıma açıktır. Çavuşcugöl linyit ocağı aynı zamanda Konya-Afyon demiryolu güzergâhı üzerindedir. Sahanın yer bulduru haritası ve uydu görüntüsü Şekil 1'de görülmektedir.

Sahanın temelini paleozoik yaşlı metamorfik şistler oluşturur. Bunun üzerine jura-kretase yaşlı kristalize kireçtaşları, neojene ait pliosen çağında teşekkül etmiş kömürlü seri ve daha sonra kireçtaşı molozları, killi kumlu marnlı karışık seri ve nihayet moloz örtüleri ve alüvyonlar gelmektedir (Çağlar, 1989). 
Ekskavatör-kamyon yöntemi sahada kömür üretimi ve dekapaj işlemleri için kullanılan yöntemdir. Bu sahada kömür üstü dekapajı, kömür üretimi, ara kesme ve kömür üstü temizliği gibi madencilik faaliyetleri yüklenici firmalar tarafından gerçekleştirmektedir.

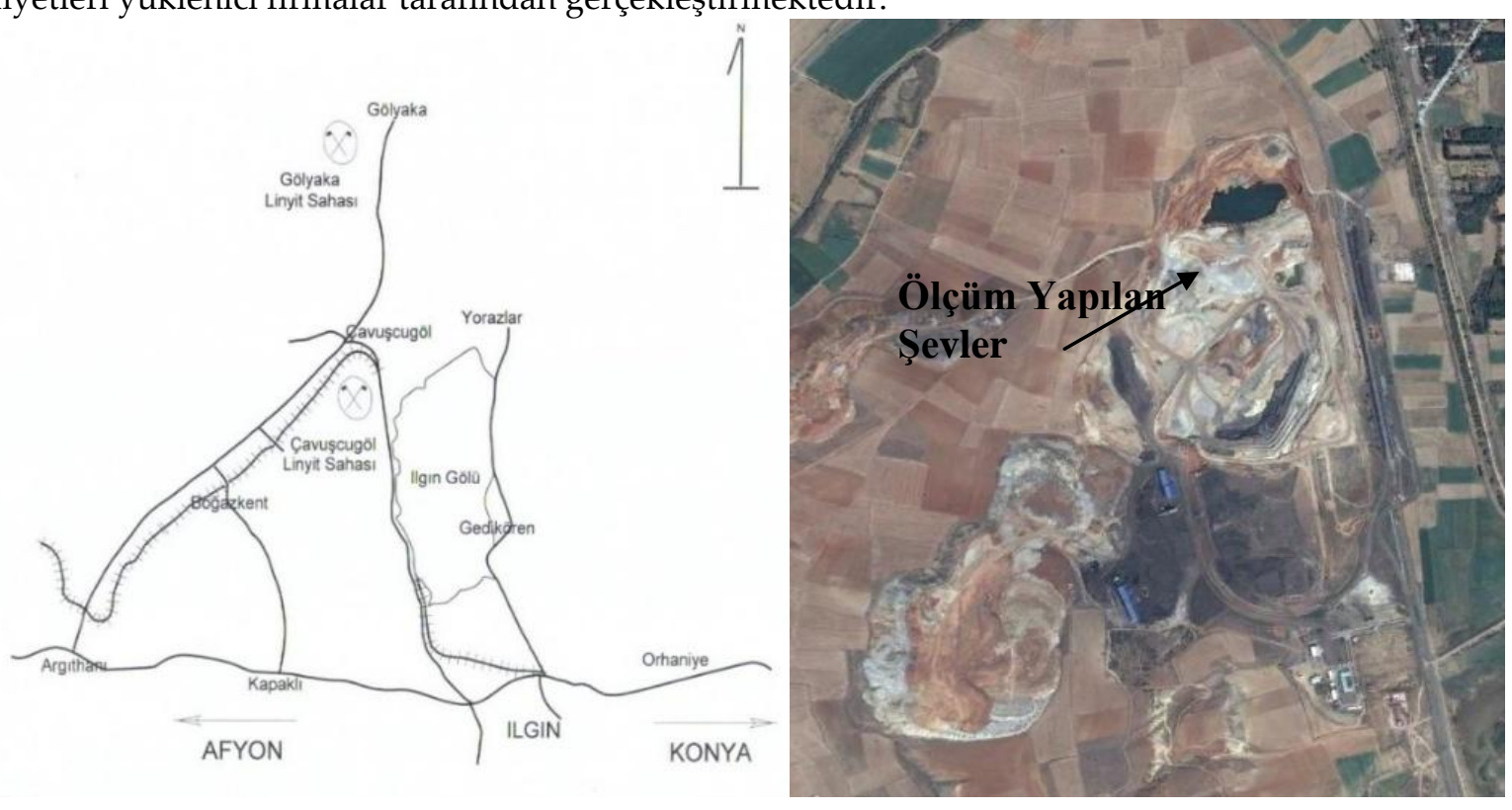

Şekil 1. TKİ-ILİ Ilgın Çavuşcugöl ocağının yer bulduru haritası ve uydudan görüntüsü Figure 1. Site location and satellite image of TKİ-GLİ Ilgın Çavuşcugöl lignite mine

\section{ÖLÇÜM SİSTEMİ(MEASUREMENT SYSTEM)}

Ölçüm sisteminin esasını jeodezik ağ oluşturmak yolu ile ocakta jeodezik ölçümler alınması oluşturmaktadır. Bir jeodezik ağ şevdeki hareketli bölgenin etrafında, üstünde ve hareketin olmadığ1 bölgelerde kontrol amaçlı oluşturulan prizmalardan meydana gelir. Şevdeki ölçüm istasyonundan prizmalara olan açlar ve mesafeler hareketin izlenmesi amacıyla düzenli olarak ölçülür. Sabit kontrol noktalarının stabil bir yüzey üzerinde olması çok önemlidir. Zemin hareketlerinin jeodezik ölçülerle saptanması için uygulanan yöntem, incelemeye konu olan bölgenin, hareket beklenen, hareket beklenmeyen ve hareketinden kuşku duyulan kesimlerinin jeodezik kontrol ağı oluşturmak ve bu ağın belli zaman tekrarlama ölçüsü sonucunda elde edilecek nokta koordinatlarının zamanla değişiminin matematik istatistik test yöntemleriyle analizi esasına dayanır. İstasyonların bulunduğu hareketli bölgede üç adet sabit poligon noktası tesis edilmiş ve hareketin olduğu bu üç noktada teodolit yardımı ile belirli zaman aralıklarıyla $\mathrm{x}, \mathrm{y}$ ve $\mathrm{z}$ koordinatları okunmuş ve kaydedilmiştir.

Sahada yapılan incelemelerde şev üstlerinde çekme çatlaklarının oluştuğu ve bazı lokal kaymaların olduğu tespit edilmiştir (Şekil 2). Bu çalışmada, olası bir duraysızlık halinin tespiti ve gerekli önlemlerin alınabilmesi açısından bu bölgelerde oluşan zamana bağlı deformasyonların takip edilmesine ve bu izlemenin jeodezik yöntem ile yapılmasına karar verilmiştir. Bu kapsamda, deformasyon oluşumu beklenen yerlerde 3 adet nokta belirlenerek bir kontrol ağ noktalardan ölçümler alınmıştır. Ölçümlere 5 Kasım 2018 tarihinde başlanarak 25 Şubat 2019 tarihinde sonlandırılmıştır. Toplamda 112 gün süren 23 adet ölçüm gerçekleştirilmiştir. Ölçüm sonuçları neticesinde yaklaşık 100. günden sonra sahada deformasyon hızında artış görülmesi ile birlikte şevde yetkililer tarafından önlemler alınmış ve deformasyon hareketliliği durdurulmuştur. 112 günlük süreçte 1 no'lu istasyonda $235 \mathrm{~mm}, 2$ no'lu istasyonda $346 \mathrm{~mm}$ ve 3 no'lu istasyonda da $182 \mathrm{~mm}$ toplam deformasyon (üç yönlü deformasyonun bileşkesi) tespit edilmiştir. 
Çizelge 1. Jeodezik ölçüm tarihleri Table 1. Geodetic measurement dates

\begin{tabular}{cc|cc|cc}
\hline Ölçüm No & Ölçüm Tarihi & Ölçüm No & Ölçüm Tarihi & Ölçüm No & Ölçüm Tarihi \\
\hline 1 & 5.11 .2018 & 9 & 15.12 .2018 & 17 & 25.01 .2019 \\
2 & 10.11 .2018 & 10 & 21.12 .2018 & 18 & 31.01 .2019 \\
3 & 15.11 .2018 & 11 & 25.12 .2018 & 19 & 5.02 .2019 \\
4 & 20.11 .2018 & 12 & 31.12 .2018 & 20 & 9.02 .2019 \\
5 & 25.11 .2018 & 13 & 5.01 .2019 & 21 & 15.02 .2019 \\
6 & 30.11 .2018 & 14 & 10.01 .2019 & 22 & 20.02 .2019 \\
7 & 5.12 .2018 & 15 & 16.01 .2019 & 23 & 25.02 .2019 \\
8 & 10.12 .2018 & 16 & 20.01 .2019 & & \\
\hline
\end{tabular}

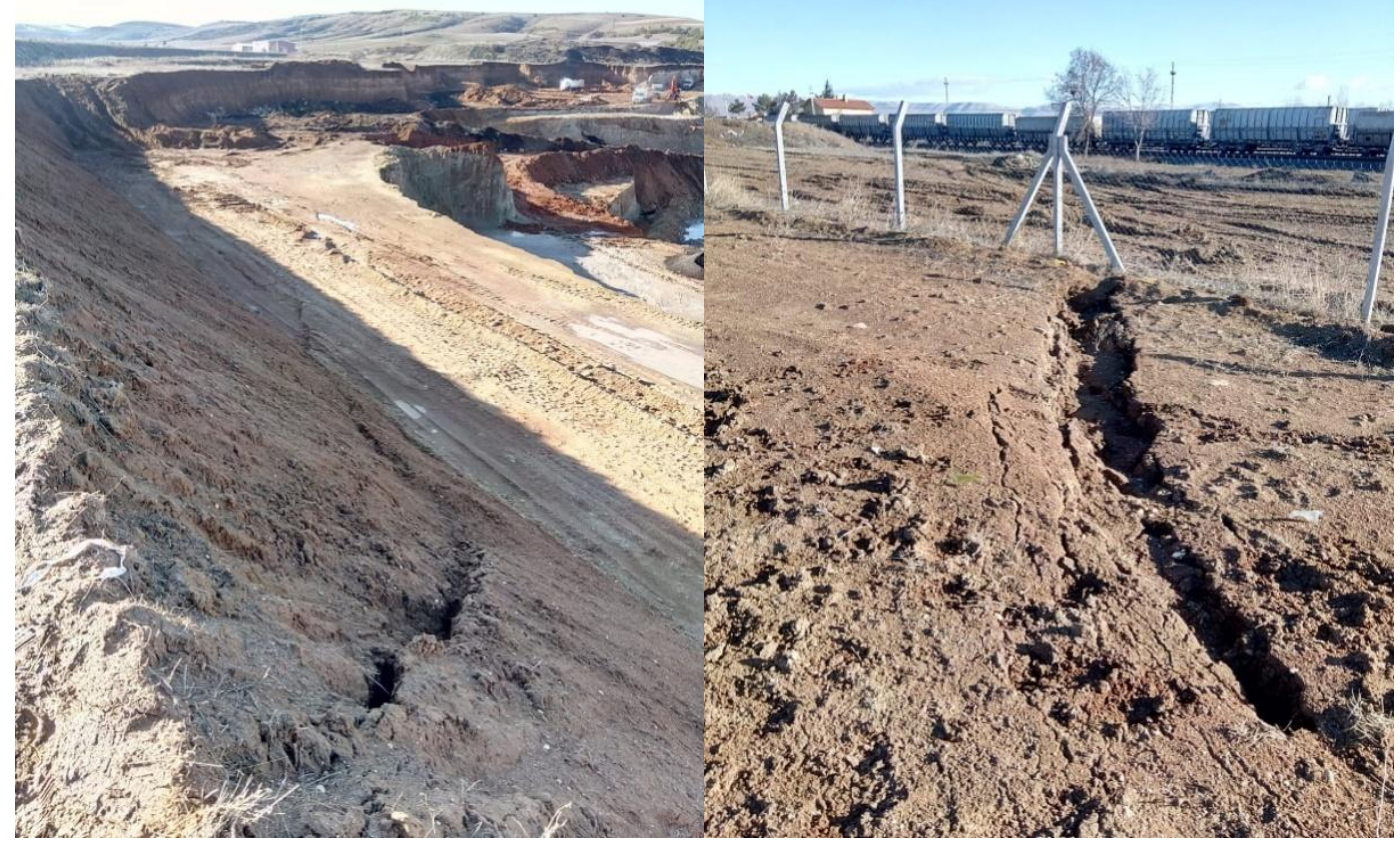

Şekil 2. Sahada görülen çekme çatlakları Figure 2. Tension cracks seen in the field

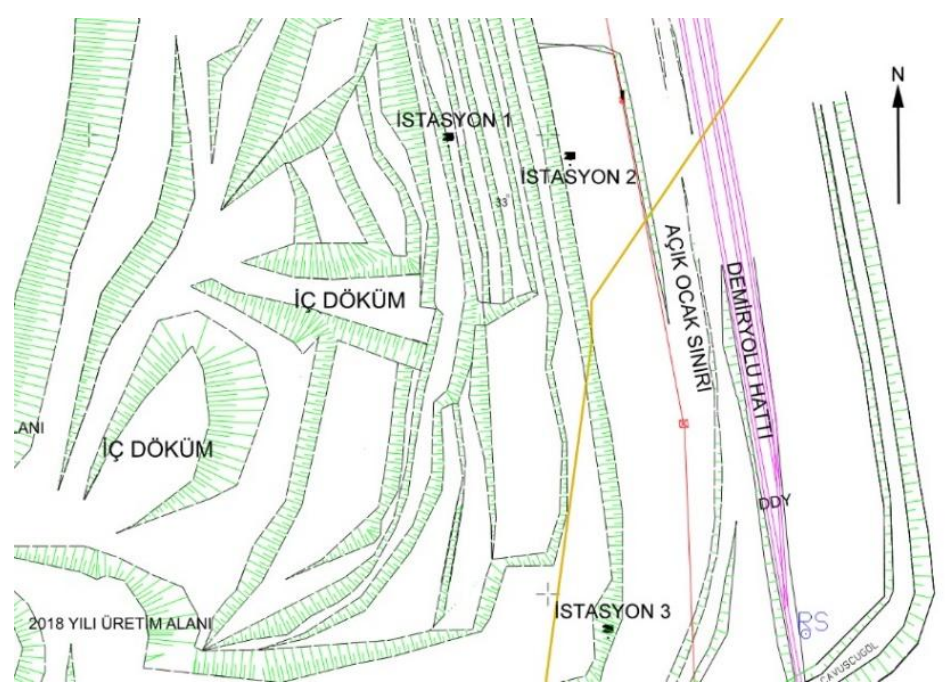

Şekil 3. Jeodezik ölçüm istasyonların kurulduğu yerler Figure 3. Points of geodetic measurement stations 


\section{MATEMATIKKSEL EŞİTLIK(MATHEMATICAL EQUATION)}

Ocakta yapılan gözlemler ve ocak mühendislerinin yaptığı çalışmalar neticesinde şevlerde hareketlilik olduğu belirlenmiştir. Özellikle Çavuşcugöl tren istasyonu tarafında oluşabilecek bir duraysızlığın ciddi sonuçlar doğurabileceği düşüncesiyle bu hareketliliğin ne tür bir eğilim içerisinde olduğunun belirlenmesi önem kazanmıştır. Bu kapsamda, özellikle çekme çatlağının bulunduğu bölgeler dikkate alınarak ocak şevlerinde ölçüm noktalarının kurulması gereken koordinatlar tespit edilmiştir. Bu noktalara ölçüm istasyonları tesis edilmiş ve periyodik aralıklarla ölçümler yapılmıştır. Yapılan bu ölçümlerden bir veri tabanı oluşturulmuştur. Ardından, oluşturulan bu veri tabanı istatistiki olarak incelenmiş ve genel eğilimi belirlenmiştir. Hareket eğilimi belirlenen her bir istasyon için bir matematiksel eşitlik geliştirilmiştir. Elde edilen matematiksel eşitlik neticesinde eldeki verilerden yola çıkarak ölçüm yapılmayan herhangi bir zamanda oluşabilecek deformasyon miktarı ve hızının belirlenmeye çalışılmıştır.

Kennedy ve diğ. (1970) tarafından yapılan bir çalışmada, Şili'deki bir bakır açık ocağında zamana bağlı deformasyonun üstel bir bağıntıya sahip olduğu belirlenmiştir. Benzer olarak, Zvelebil ve Moser, (2001) tarafından yapılan bir diğer çalışmada ise aynı tipte bir bağıntının Çek Cumhuriyeti-Kuzey Bohemia'da uluslararası bir yol kenarında kumtaşı formasyonunda meydana gelen bir kaymada gerçekleştiği vurgulanmış ve zamana bağlı izleme sonucunda şev kayması yaklaşık 2 ay önceden tahmin edilebilmiştir. Ülkemizde de Ilgın ve Yatağan linyit açık ocaklarında bu alanda benzer çalışmalar gerçekleştirilmiştir. Oluşan çekme çatlakları üzerinde deformasyon ölçümleri yapılarak zamana bağlı deformasyon oluşumu yüksek regresyonlu bağıntılar ile modellenmiş ve gerçek veriler ile eşitlikten elde edilen veriler karşılaştırılmıştır (Özşen ve Özkan, 2013, Özşen ve Kurt, 2015, Özşen, 2017). Bu çalışmada ise Özşen ve diğ.'nin (2019) geliştirmiş olduğu bağıntı uygulanmış ve geliştirilerek Eşitlik 1'deki değişiklik ile revize edilerek kullanılmıştır.

$U=C_{1} \log (t)+C_{2} t+\left(C_{3} t\right)^{C_{4}}$

Burada,

U: Deformasyon miktarı (mm)

$t$ : Zaman (gün)

$C_{1}, C_{2}, C_{3}$ ve $C_{4}:$ Uygun istatistiksel parametrelerdir.

Yapılan istatistiksel analizler neticesinde elde edilen bağıntılar ve bu bağıntılar ile oluşturulan grafikler sırasıyla Çizelge 2 ve Şekil 4' de sunulmuştur.

Çizelge 2. Geliştirilen eşitlikler ve regresyon katsayıları Table 2. Equations developed and regression coefficients

\begin{tabular}{ccc}
\hline İstasyon No & Eşitlik & Regresyon Katsayisi \\
\hline 1 & $U=106,3 \log (t)-14,46 t+(3,216 t)^{1,225}$ & 0,95 \\
2 & $U=105,9 \log (t)-2,053 t+(0,03132 t)^{3,469}$ & 0,99 \\
3 & $U=30,31 \log (t)-0,1581 \mathrm{t}+(0,0366 t)^{9,598}$ & 0,98 \\
\hline
\end{tabular}

Matematiksel modelleme çalışmaları kapsamında Eşitlik 1'deki bağıntının yüksek regresyon katsayılarından da anlaşılacağı üzere gerçek arazi deformasyon verileri ile çok iyi uyum gösterdiği ortaya çımıştır. Çizelge 2'deki eşitlikler dikkate alınarak oluşturulan eğriler Şekil 4'de görüldüğü gibidir. Zamana bağlı deformasyon hareketlerinin incelenmesi neticesinde, İstasyon 1 için regresyon katsayısı 0,95, İstasyon 2 için 0,99 ve İstasyon 3 için 0,98 olarak belirlenmiştir. 


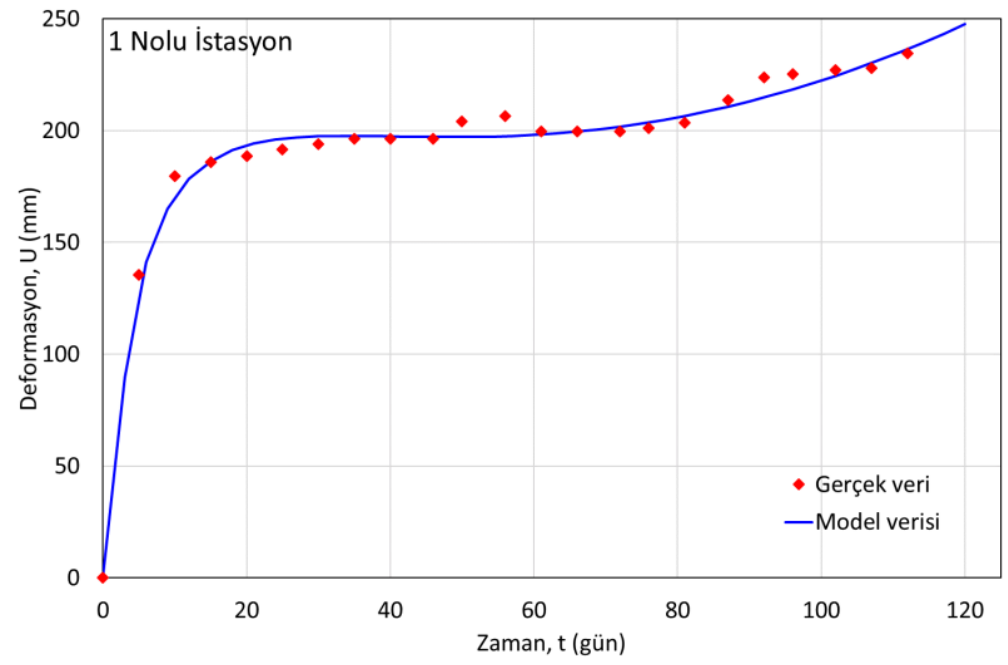

(a) 1 no'lu istasyon

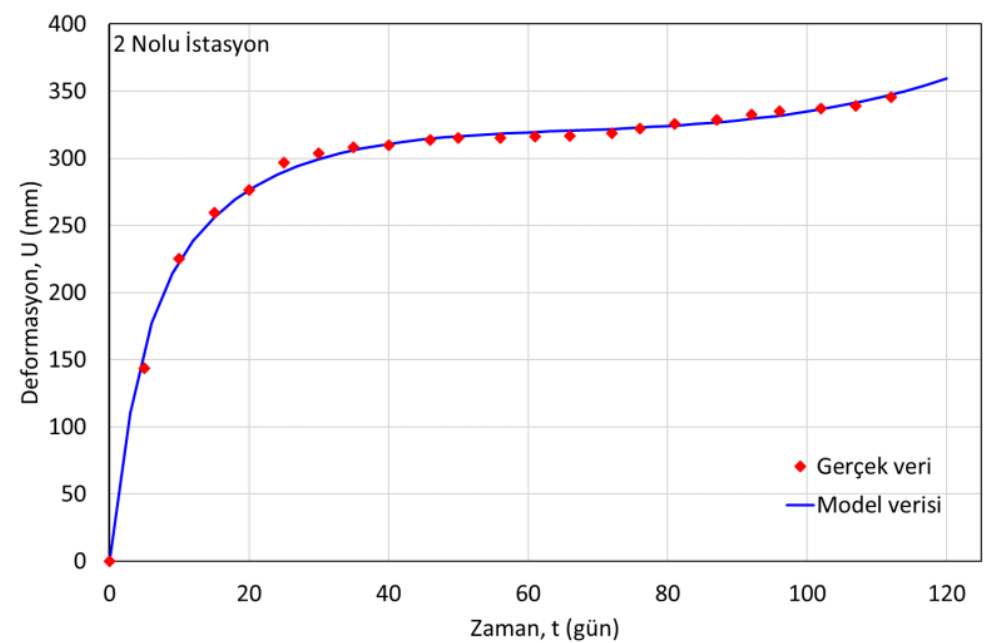

(b) 2 no'lu istasyon

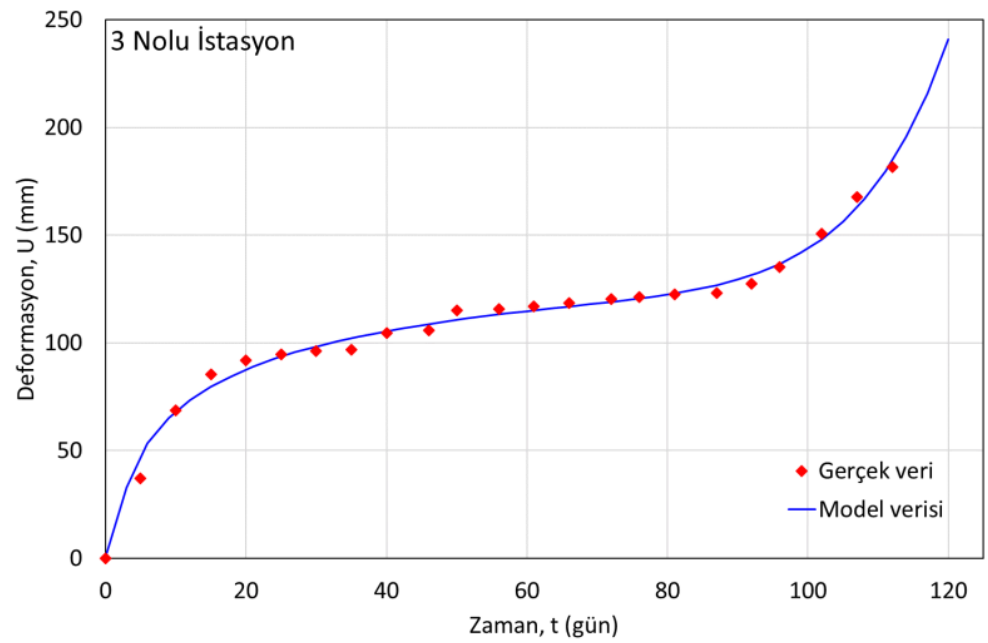

(c) 3 no'lu istasyon

Şekil 4. Sahadan elde edilen gerçek deformasyon verileri ile matematiksel modelden edilen veriler Figure 4. In-situ deformation data obtained from the field and the mathematical model data 
Çizelge 3. Araziden elde edilen deformasyon miktarları ile eşitliklerden elde edilen deformasyon miktarlarının karşılaştırılması

Table 3. Comparing the deformation data from in-situ field measurements and the equations

\begin{tabular}{ccc}
\hline $\begin{array}{c}\text { İstasyon } \\
\text { No }\end{array}$ & $\begin{array}{c}\text { Arazi verisi* } \\
(\mathrm{mm})\end{array}$ & $\begin{array}{c}\text { Eşitlik sonucu* } \\
(\mathrm{mm})\end{array}$ \\
\hline 1 & 235 & 239 \\
2 & 346 & 347 \\
3 & 182 & 185 \\
\hline
\end{tabular}

Ayrıca elde edilen eşitlik gerçek ölçüm verileri ile denenmiş ve bu sonuçlar Çizelge 3'de sunulmuştur. Çizelge 2'de görülen fonksiyonlarda 112 gün olan nihai ölçüm zamanı yerine konulduğunda Eşitlik 2'den Çizelge 3'deki değerler elde edilmiştir. Bu değerlerden de görüleceği üzere eşitlikten gerçek veriye çok yakın sonuçlara ulaşılmıştır. Bu değerlerin karşılaştırmalı grafikleri oluşturulduğunda aralarında doğrusal bir bağıntının olduğu belirlenmiştir (Şekil 5). Arazi deformasyon verileri $\left(A_{v}\right)$ ile eşitlik deformasyon verileri $\left(E_{v}\right)$ arasındaki bağıntılar Eşitlik 2' de verilmiştir. Eşitlik 1'den elde edilen sonuç verileri ile araziden elde edilen gerçek veriler karşılaştırıldığında iki parametre arasındaki regresyon katsayısı 0,99 olarak tespit edilmiştir. Bu durumda Eşitlik 1'den elde edilen değerlerin gerçek arazi verisine neredeyse tam olarak ulaştığı sonucuna varılmıştır.

$A_{v}=0,9855 E_{v}+6,3462$

Burada;

$A_{v}$ : Araziden elde edilen gerçek deformasyon verisi (mm),

$E_{v}$ : Eşitlik 1'den elde edilen veri (mm)

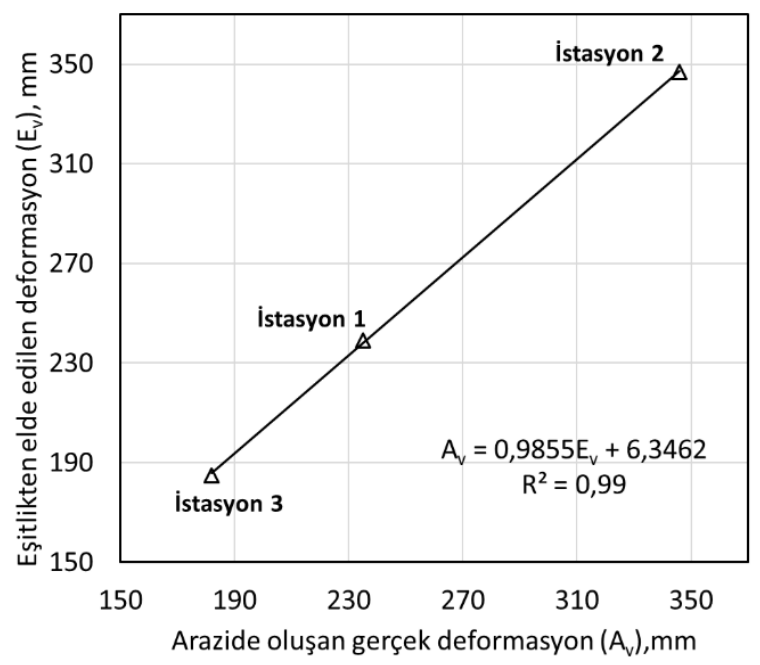

Şekil 5. Arazi deformasyon verileri ile eşitliklerden elde edilen deformasyon verilerinin karşılaştırılması

Figure 5. Comparing the in-situ data and the data obtained from equations

\section{SONUÇLAR(CONCLUSIONS)}

Bu çalışmada, Ilgın Çavuşcugöl linyit açık ocağı doğu şevlerinin çekme çatlakları ile belirti veren duraysız olduğu tespit edilen bölgesinde toplam 112 gün süren bir deformasyon izleme ve değerlendirme uygulaması gerçekleştirilmiştir. Şev duraysızlığı olduğu belirlenen alanlarda jeodezik kontrol ağı oluşturularak deformasyon miktarları düzenli aralıklarla ölçülmüştür. Yatay ve düşey yönlerindeki deformasyonlar belirlenmiş, ardından tüm yönlerdeki deformasyonların bileşkesi alınarak 
toplam deformasyon miktarı belirlenmiştir. Bu ölçümler ışığında 112 günlük ölçüm süreci neticesinde; 1 no'lu istasyonda $235 \mathrm{~mm}, 2$ no'lu istasyonda $346 \mathrm{~mm}$ ve 3 no'lu istasyonda $182 \mathrm{~mm}$ toplam deformasyon tespit edilmiş ve tüm istasyonlarda hareketliliğin ocağın batı yönüne doğru olduğu görülmüştür.

Ocakta oluşan bu deformasyon hareketleri ileri tarihlerde oluşabilecek duraysızlık problemlerinin ne şekilde oluşabileceğinin sorgulanmasına neden olmuştur. Bu nedenle önceki çalışmaların da ışığında sonuç değerlerinin tespitinde yüksek regresyon katsayılı sonuçlar veren bir eşitlik geliştirilmiş ve verilere tatbik edilmiştir. Elde edilen matematiksel eşitliklerde amaç, gerçek verilerin kullanılarak bilinmeyen verilere ulaşılmasıdır. Bu sayede farklı tarihlerde bu ocakta oluşabilecek deformasyon miktarlarının tahmin edilmesi mümkün olabilecektir.

Ocak sürekli gözlem altında tutulmalı ve deformasyon hız ve ivmesi gibi bazı parametreler göz önüne alınarak kritik hız ve ivme değerlerine yaklaşıldığında bu değerler kritik sınırların üstüne çıkarsa mutlaka mevcut bölgede önlem alınmalıdır. Hızlanma eğilimin devam etmesi halinde hızlanmayı azaltacak tedbirler alınmalıdır. Yapılacak delme-patlatma çalışmaları, zaman içerisinde bölgede yapılan çalışmanın yoğunluğundaki değişimler, şiddetli yağış veya bölgede oluşabilecek depremler gibi bazı parametrelerin değişmesi de deformasyon hızında artışlara neden olabilir. Şevlerin sürekli izlenmesi ve elde edilen sonuçların acilen değerlendirilmesi istenmeyen durumların önüne geçilmesi açısından önemlidir.

Bu çalışmada ele alınan bölgedeki hız ve ivme değerlerinin normal değerler içerisinde seyretmekte olduğu ancak son dönemde hızlanma eğilimine girdiği tespit edilmiştir. Yapılan müdahaleler ile değerler tekrar kritik değerlerin altına çekilmiş ve olası tehlikeli bir durumun önüne geçilmiştir. Bu çalışmadaki denklemlerin kısa vadeli sonuçlar için kullanılması uygun olacaktır. Yukarıdaki etkenlerin değişimi ile farklı durumlar için denklemler revize edilmeli ve belirlenen yeni duruma göre hareket edilmelidir.

\section{TEŞEKKÜR(ACKNOWLEDGEMENTS)}

Yazarlar, bu çalışmanın yapılmasında her türlü yardımı gerçekleştiren TKİ-GLİ Ilgın-Çavuşcugöl İşletmesi ve Düzgün İş Mak. İnş. Mad. San. ve Tic. A.Ş. yönetici, mühendis ve çalışanlarına teşekkür ederler.

\section{KAYNAKLAR(REFERENCES)}

Akbulut, İ., Çam, İ., Aksoy, T., Çağlan, D., Ölmez, T., 2013, “Açık ocaklarda şev duraysızlığı ve geriye dönük analizlere bir örnek: Afşin-Elbistan Kışlaköy açık kömür ocağı", Maden Tetkik ve Arama Dergisi, c.147, pp.115-126.

Carlà, T., Intrieri, E., Di Traglia, F., Nolesini, T., Gigli, G., Casagli, N., 2017, "Guidelines on the use of inverse velocity method as a tool for setting alarm thresholds and forecasting landslides and structure collapses" Landslides, Vol.14, pp.517-534.

Çağlar, A.T., 1989, "Haremi Köy-Ilgın (Konya) çevresinin jeolojisi ve linyit etütleri, S.Ü. Fen Bilimleri Enstitüsü, Yüksek Lisans Tezi, 42s., Konya

Dereli, E., 2010, “Çetinkaya Divriği (Sivas) arasındaki tren yolu güzergahı boyunca şev duraylılıklarının araştırılması ve kinematik kontrollü olası duraysızlık modelinin üretilmesi", C.Ü. Fen Bilimleri Enstitüsü, Yüksek Lisans Tezi, 64s., Sivas.

Karagöz, S.D., Koca M.Y., 2016, “Alipaşa açık ocak albit madeninde meydana gelen heyelanın GPS kullanılarak izlenmesi ve oluşum nedenleri", Jeoloji Mühendisliği Dergisi, c.40, s.1, pp. 27-52.

Kennedy, B.A., Niermeyer KE., Fahm BA., "Slope monitoring systems used in the prediction of a major slope failure at The Chuquicamata Mine, Chile", Planning Open Pit Mines Symposium, Johannesburg, pp.215-225, 1970.

Kulaksız, S., 2012, "Şevlerde hareket izleme teknikleri", Madencilikte Çevre Yönetimi, Afyon, ss. 47-48.

Özgenoğlu, A., 2005, "Açık işletmelerde şev stabilitesi analizi", Maden Mühendisliği Açık Ocak İşletmeciliği El Kitabı, Ankara, ss. 337-387. 
Özşen, H., Özkan, İ., 2013, “TKİ-GLİ Ilgın linyit açık ocağı batı şevlerinde oluşan gerilim çatlaklarında oluşan deformasyonların izlenmesi ve zamana bağlı matematiksel modellenmesi", S.Ü. Müh. Bilim ve Tekn. Derg., c.1, s.3, ss. 37-44.

Özşen, H., Kurt, A.C., 2015, "Soma linyit açık ocağında oluşan deformasyonların inklinometrik yöntemle izlenmesi", S.Ü. Müh. Bilim ve Tekn. Derg., c.3 s.3, ss. 59-65.

Özşen, H., 2017, "Yatağan Eskihisar linyit açık ocağı batı şevlerinde oluşan deformasyonların jeodezik yöntemle izlenmesi ve matematiksel modellenmesi", S.Ü. Müh. Bilim ve Tekn. Derg., c.5, s.3, ss. 329-340.

Özşen, H., Özkan, İ., Mesutoğlu M., 2019, “An approach on modelling of in-situ deformations for unstable coal mine slopes", Bulletin of Engineering Geology and the Environment, Vol. 78, pp. 3191-3203.

Vanneschi, C., Eyre, M., Burda, J., Žižka, L., Francioni, M., Coggana, J.S., 2018, "Investigation of landslide failure mechanisms adjacent to lignite mining operations in North Bohemia (Czech Republic) through a limit equilibrium/finite element modelling approach", Geomorphology, Vol. 320, pp. 142-153.

Venter, J., Kuzmanovic, A., Wessels, S.D.N., 2013, "An Evaluation of the CUSUM and inverse velocity methods of failure prediction based on two open pit instabilities in the Pilbara", Slope Stability, pp. 1-16.

Zvelebil, J., Moser, M., 2001, "Monitoring based time-prediction of rock falls: Three case-histories", Physics and Chemistry of the Earth (B), Vol.26, No.2, pp.159-167. 